\title{
Elements of intensive care bereavement follow-up services: A European survey
}

\section{Egerod, I}

http://hdl.handle.net/10026.1/14226

10.1111/nicc.12459

Nursing in Critical Care

Wiley

All content in PEARL is protected by copyright law. Author manuscripts are made available in accordance with publisher policies. Please cite only the published version using the details provided on the item record or document. In the absence of an open licence (e.g. Creative Commons), permissions for further reuse of content should be sought from the publisher or author. 
Elements of intensive care bereavement follow-up services: A European survey

Ingrid Egerod PhD MSN RN; Gudrun Kaldan MHS RN; John Albarran RN, BSc (Hons), Msc, DPhil, NFESC; Maureen Coombs PhD, RN; Marion Mitchell PhD RN Grad Cert (Higher Educ); Jos M. Latour PhD, RN

Journal: Nursing in Critical Care

Acceptance date: 30 May 2019

\section{Authors}

Corresponding author:

Ingrid Egerod PhD MSN RN, Professor of clinical nursing

University of Copenhagen, Rigshospitalet, Intensive Care Unit 4131

Blegdamsvej 9, DK 2100 Copenhagen O, Denmark

Phone: +45 35452896

Email: ingrid.egerod@regionh.dk

Gudrun Kaldan MHS RN

Copenhagen University Hospital Rigshospitalet

Centre for Cancer and Organ Diseases, Research Unit 7831

Blegdamsvej 9, DK 2100 Copenhagen O, Denmark

Email: gudrun.kaldan.01@regionh.dk

John Albarran RN, BSc (Hons), Msc, DPhil, NFESC

Associate Professor in Critical and Cardiovascular Nursing,

Co-Editor of Nursing in Critical Care

E-mail: john191cr@talktalk.net

Maureen Coombs $\mathrm{PhD}, \mathrm{RN}$

School of Nursing and Midwifery, Faculty of Health and Human Sciences,

University of Plymouth, 7 Portland Villas, Room 201, Drake Circus,

Plymouth PL4 8AA, United Kingdom

Email: Maureen.coombs@plymouth.ac.uk

Marion Mitchell PhD RN Grad Cert (Higher Educ), Professor of Critical Care

Menzies Health Institute Queensland, School of Nursing and Midwifery, Griffith University, and Princess Alexandra Hospital, Woolloongabba, Australia.

Email: Marion.mitchell@griffith.edu.au

Jos M. Latour PhD, RN, Professor

School of Nursing and Midwifery, Faculty of Health and Human Sciences,

University of Plymouth, 8-11 Kirkby Place, Room 205, Drake Circus,

Plymouth PL4 8AA, United Kingdom

E-mail address: jos.latour@plymouth.ac.uk

Conflicts of interest: The authors have no conflicts of interest to declare 


\section{ABSTRACT}

Background: Despite technological innovations and continuous improvement in evidence-based treatments, mortality in the intensive care unit remains high. Consequently, a large group of family members may be in need, and benefit from bereavement follow-up support.

Aim: To explore elements, organization, and evaluation of ICU bereavement services in European countries. Specific objectives were to investigate: 1) the model of bereavement follow-up services (elements of support), 2) the workforce model (organization of staff), 3) the evaluation model (evaluation strategies).

Study design: Cross-sectional survey of conference delegates.

Methods: A paper and pen questionnaire including a cover letter assuring the respondents of anonymity and confidentiality was distributed to 250 delegates during the opening ceremony of the 2017 European federation of Critical Care Nurses associations (EfCCNa) Congress in Belfast. The questionnaire was developed from a previously validated tool describing bereavement care practices in intensive care units including questions about the content and organization of bereavement follow-up services. Frequencies were calculated in yes/no questions and content analysis was applied in additional free text comments.

Results: We received 85 responses from publicly employed nurses, mainly in mixed adult ICUs. Respondents were 48 (56.5\%) bedside nurses and the rest represented clinical nurse specialists, researchers, managers, or academic nurses. Bereavement follow-up had existed about 1-15 years. Important follow-up elements were: viewing the deceased in the unit 77 (90.6\%), providing followup information 67 (79.8\%), sending a letter of sympathy 17 (20\%), and calling the family to arrange a meeting $27(31 \%)$. 
Conclusion: Bereavement follow-up is common, but variable at European intensive care units. We recommend the development, implementation, and evaluation of evidence-based, but culturespecific, bereavement follow-up guidelines for European intensive care units.

Relevance to Clinical Practice: More critical care nurses are realizing the need for bereavement follow-up guidelines. This paper provides an overview of common elements that might be considered. 


\section{INTRODUCTION}

More people survive critical illness in the intensive care unit (ICU). The ICU-population, however, is getting older and mortality is still considerable (Cuthbertson et al., 2007). This leaves a large group of bereaved family members dealing with their loss in an unfamiliar and technological environment. Family members of ICU patients risk psychological morbidity during and after the ICU stay (Needham et al., 2012, Goldfarb et al., 2017) with evidence of bereaved family members at risk of developing symptoms of complicated grief (Azoulay et al., 2005).

In general, most people experience uncomplicated grief with few signs of impairment at six months after their loss, but about a third of close family members might experience symptoms of prolonged grief and depression (Nielsen et al., 2016). Family members of patients in ICU are at risk of mental health morbidity during and after the patient's ICU stay. One observational study reported that $73 \%$ of family members experienced anxiety and 35\% depression in the days preceding their relative's ICU discharge or death (Pochard et al., 2005). Another study showed that $34 \%$ of ICU family members met criteria for at least one psychiatric illness and 5\% experienced complicated grief disorder within one year of the patient's death (Siegel et al., 2008). Complicated grief was identified after a year in $46 \%$ of bereaved family members of ICU patients in a study using the Inventory of Complicated Grief (Anderson et al., 2008). Psychological morbidity is associated with increased uptake of health services and increased risk of death (Stroebe et al., 2007). The current evidence suggests that family members of a patient that dies in the ICU are at risk of complicated grief. ICU bereavement follow-up services might help to alleviate grief in family members, albeit little is known about provision of these services across Europe.

Supporting the family is a natural part of critical care nursing (Coombs et al., 2012). While social networks are effective sources of support for most people during their bereavement, those at risk of developing complicated grief may benefit from formal bereavement support services. Over 
the past 30 years, ICUs have worked to support grieving families both at time of death and afterwards. Unit-based quality initiatives have been introduced to support families during the time leading up to end-of-life care (Lautrette et al., 2007) and bereavement follow-up services have been developed to support ICU families.

Several models of intensive care bereavement follow-up have been reported in the literature (Garland, 2011, Ross, 2008, Williams et al., 2003). These demonstrate differences in the service models used to support families after death in ICU settings, for example with regards to timing of contact with bereaved families, use of sympathy cards and offering of return visits to the ICU. Studies in this area are mainly limited to single site case reporting. An exception to this is the reporting on family bereavement programs across Australia (Valks et al., 2005). In this survey study, responses from 99 Australian adult ICUs were received (84.6\% response rate). Most of the units surveyed offered components of bereavement programs, such as liaising with critically ill patients, family and friends (93\%), viewing of the deceased (92\%), debriefing the staff (78\%), and communicating death with family members (77\%). Less than a third provided additional follow-up services in the form of telephone calls to bereaved families or sympathy cards. Verbal feedback from staff and families was the primary method of evaluation on the impact of these.

A recent survey of ICU nurse managers investigated the provision of family bereavement support in ICUs across New Zealand and Australia and found that $12(50 \%)$ and $34(28 \%)$ of responding units in the two countries respectively offered a bereavement follow-up service (Mitchell et al., 2016). Similarly, a survey was conducted with ICU nurse leaders in the US wherein most respondents $(n=237)$ reported that their ICUs did not provide organized bereavement followup services, but some nurses offered informal support in the form of condolence cards or brochures (McAdam and Erikson, 2016). Similar results were found in a recent Danish study (Egerod et al., 
2018). In European countries, there is limited knowledge regarding the scope and models of intensive care bereavement practice.

\begin{abstract}
AIM
To explore elements, organization, and evaluation of ICU bereavement services in European countries. Specific objectives were to investigate: 1) the model of bereavement follow-up services (elements of support), 2) the workforce model (organization of staff), 3) the evaluation model (evaluation strategies).
\end{abstract}

\title{
DESIGN AND METHODS
}

\section{Sample population}

We conducted a cross-sectional, self-administered, paper-and-pen survey. The questionnaire included a cover letter explaining the purpose of the study and assuring the respondents of anonymity and confidentiality. It was distributed to 250 delegates during the opening ceremony of the 2017 European federation of Critical Care Nurses associations (EfCCNa) Congress in Belfast. Each delegate was handed the questionnaire and completed questionnaires were returned during the conference to a box at the registration desk. Critical care nurses working in all types of intensive care units, hospitals, teaching or academia in Europe were eligible for inclusion.

\section{Data collection tool}

The questionnaire was developed by the authors from a previously validated tool (Egerod et al., 2018, Mitchell et al., 2016) and was piloted by five intensive care nurses. It consisted of four sections and 32 items including space for free text responses. The sections were: Section 1: Demographics (items 1-8), Section 2: Model of bereavement follow-up services (items 9-17), 
Section 3: Workforce model (items 18-22), and Section 4: Evaluation model (items 23-32).

\section{Data analysis}

The results were triangulated using descriptive statistics and narrative reporting to analyze data. We calculated means and frequencies. Quantitative data were managed in IBM/SPSS version 22 and open text responses were analyzed using content analysis (Vaismoradi et al., 2013).

\section{Ethical considerations and research governance}

According to the Danish Data Protection Agency approval was not required for the survey because the participants remained anonymous and provided consent by answering the survey. The Danish Ethical Committee did not request further approval if all data were analyzed and stored in Denmark (reference no. 17002610). Data were analyzed and stored in accordance with General Data Protection Regulation (GDPR) (https://www.eugdpr.org/) and the Declaration of Helsinki (WMA, 2008). The participants were informed on the first page of the questionnaire that participation was voluntary and confidential.

\section{RESULTS}

About 400 delegates attended the 2017 EfCCNa conference in Belfast. The survey was disseminated to the conference delegates attending the opening ceremony and made available in a box at the registration desk. We distributed 250 questionnaires and of which 85 were completed at the end of the conference. The results are presented in the order of the four sections in the survey. Quotes from the analyzed free text data are used to provide additional detail about the ICU bereavement services. Most quotes are from the Nordic countries as respondents from the remaining countries stated that bereavement follow-up was not offered. 


\section{Section 1: Demographics}

Respondents resided in 42 cities in 18 European counties. Most were from Northern Europe (75 of 85), particularly the Scandinavian countries. Half of the respondents worked as ICU bedside nurses; the remaining were clinical nurse specialists, managers, and nurses in academic, teaching or research positions (Table 1). Most of the respondents were educated beyond basic nursing school, e.g. critical care nurse $(\mathrm{CCN})$ certification, and Bachelor's, Master's and PhD degrees. Most worked at public hospitals; predominantly level III ICUs. Most respondents worked at adult or adult/pediatric mixed medical/surgical ICUs. The capacity of ICUs ranged from 5 to 42 beds (mean 15 beds). 
Table 1 Demographics

\begin{tabular}{llr}
\hline $\begin{array}{l}\text { Respondents and their } \\
\text { workplace }\end{array}$ & Number (\%) \\
\hline Role of respondents & ICU bedside nurse & $48(56.5)$ \\
& Clinical nurse specialist & $10(11.8)$ \\
& Nurse manager & $11(12.9)$ \\
& Nurse researcher & $9(10.6)$ \\
& Nurse academic/educ. & $4(4.7)$ \\
& Other & $4(4.7)$ \\
Highest level of education & Critical Care Nurse (CCN) & $21(24.7)$ \\
& certification & $11(12.9)$ \\
& Nursing diploma & $11(12.9)$ \\
& Bachelor's degree & $32(37.6)$ \\
& Master's degree & $8(9.4)$ \\
& PhD degree & $1(1.2)$ \\
Other & \\
Hospital type & Public & $84(98.8)$ \\
ICU Level & Private & $1(1.2)$ \\
& Level 1 & $6(7.1)$ \\
ICU patient age & Level ll & $24(28.2)$ \\
Level lll & $54(63.5)$ \\
ICU sub-specialty & Adult & \\
& All ages & $58(68.2)$ \\
& Pediatrics & $24(28.2)$ \\
& & $3(3.5)$ \\
& Medical/surgical & $67(78.8)$ \\
& Medical & $2(2.4)$ \\
& Surgical & $8(9.4)$ \\
& Cardiac & $5(5.9)$ \\
& Thoracic surgical & $2(2.4)$ \\
& $5-42$ beds (mean 15) & \\
\hline
\end{tabular}

\section{Section 2: Model of bereavement follow-up services}

Among the participants (representing 42 cities), 35 stated that their ICU had bereavement follow-up services and 11 of these stated that services had existed more than 10 years. Forty-eight responded that their unit did not offer bereavement support. None of the respondents reported the use of a guideline for bereavement follow-up. Typical elements of bereavement follow-up were: viewing of the deceased in ICU or in a room at the hospital mortuary, information on hospital- or communitybased support, condolence letters, or a phone call from a nurse or other staff member (Table 2). 
Table 2 Elements of bereavement follow-up services

\begin{tabular}{ll}
\hline Elements & $\mathrm{n}(\%)$ \\
\hline Viewing in ICU & $77(90.6)$ \\
Information on hospital-based support & $52(61.2)$ \\
Viewing in hospital mortuary & $45(52.9)$ \\
Phone call from nurse & $27(31.0)$ \\
Sympathy card, condolence letter or e-mail & $17(20.0)$ \\
Information on community-based support & $15(17.6)$ \\
\hline
\end{tabular}

\section{Specific elements of bereavement follow-up}

Viewing the deceased: Respondents from 18 countries $(n=77,91 \%)$ reported viewing the deceased in ICU. Fewer nurses $(n=45,53 \%)$ assisted the family to the viewing room at the hospital mortuary. Information on support services: Respondents from most countries reported referral to hospitalbased or community-based support services either verbally or in writing.

"Family members are given brochures that include information about psychosocial support contacts and grief-process" (ID34 Finland)

"The only element in our unit is explaining the procedure of what they need to do when someone in the family dies" (ID85 Israel)

Letters of condolence: Letters were sent to the closest family (as recorded in the chart) as a gesture of sympathy and condolence by regular mail or e-mail at 3-4 weeks after the patient's death, as reported by nurses from Northern European countries $(n=17)$. Letters were sent by the nurse in charge, the secretary, or the nurse that was present when the patient died. Letters were provided:

"Nurses give a condolence card to the closest family when they come" (ID01 Belgium) 
"After two weeks" (ID46 Netherlands)

"After 3-4 weeks", "After 1 month" (ID03 UK; ID04 Ireland)

"After a year by the nurse manager to the next of kin" (ID17 N Ireland)

"Soon after the death and one year after" (ID16 N Ireland)

Phone call: Twenty-six nurses reported making a phone call to the family after 3-5 weeks and others after 2-3 months. The main reason for the call was to offer a nurse consultation and to arrange a time for this. The phone call was also an opportunity to offer sympathy.

"We call after 2-4 weeks to ask how they are doing, feelings, questions and more" (ID53

Norway)

"We telephone after the funeral. We call after 3 weeks to hear that everything is going well and that they get the help they need at this stage" (ID51 Norway)

"A call is made 3-4 weeks after death to ask how the family is doing - if they have any questions left unanswered and if they want to visit us and have a talk about what happened often with a doctor present" (ID78 Island)

"We call approximately one month after to hear how the relative deals with his/her loss" (ID52 Denmark)

"A call is made after 2 months to ask about the feelings during ICU care, and how the family is doing now" (ID56 Sweden)

"Next of kin gets a phone call for follow-up after 3 months by the nurse responsible for the deceased" (ID10 Sweden)

"We call sometimes to hear if the family needs a follow-up talk/meeting" (ID66 Denmark) 
Meeting at the ICU: Twenty-two nurses reported inviting the bereaved family to visit the ICU after the patient had died. This was offered as a chance to talk to the nurses that cared for the patient, usually within the first month after the patient's death, according to family preferences.

"We always offer to telephone next of kin 3 weeks after death to offer a meeting in ICU with ICU physician and nurse" (ID06 Norway)

"Face to face meeting if requested by family, information in bereavement card" (ID27 N Ireland)

"We send a card 4 weeks after bereavement with an offer to come back to the unit for a consultation with a nurse and/or physician" (ID48 Norway)

ICU diary: Some nurses write an ICU diary for the patient to hand over when the patient leaves the unit or when the patient comes to visit ICU. If the patient dies, some nurses give the diary to the family. ICU visits might include reading the diary and the hospital chart with the nurse or physician.

"Two nurses are responsible for the diaries that we write for the patient. Four nurses are responsible for follow-up of about 100 diaries per year" (ID59 Norway)

"Diary and visit" (ID60 Norway)

"About $20 \%$ of our patients get a diary and are contacted by telephone or a visit at the hospital" (ID74 Norway)

"A visit to the ICU and reading ICU diary and patient journal together with doctor and staff" (ID07 Sweden)

Caring elements of support: Other elements of support were extending palliative care for the patient to bereavement support for the family. If the patient was a child, the nurse assisted the parents if they wanted a lock of hair or a hand-print as a keepsake. 
“... a plaster impression of the hand, a lock of hair, some memories of the deceased” (ID46 Netherlands)

Spiritual elements of support: The participants facilitated a visit with a hospital chaplain, a memorial service at hospital chapel, or an invitation to an annual memorial service to remember the deceased. Hospitals in Ireland and Northern Ireland in particular held an annual mass for patients that had died there:

"Mass is held to remember people who have passed away in ICU" (ID05 Ireland)

"Mass once a year for all deceased relatives of family" (ID41 Ireland)

"Yearly bereavement service for all religions ICU families" (ID80 N Ireland)

"Annual mass" (ID81 Ireland)

Formal elements of support: Only few respondents reported the use of formal emotional or spiritual support by a hospital chaplain $(n=7)$, psychologist $(n=2)$, physical therapist or occupational therapist $(n=2)$, social worker $(n=5)$ or physician $(n=2)$ as a part of bereavement services.

"Hospital priest is available to families if they want it. It is not automatedly offered" (ID33 Finland)

"We can advise them to take contact if they need a priest or support group" (ID43 Norway) "If they want and need, they can visit, or we can call. We can also find others to talk to them like priest, psychologist or groups for their need" (ID51 Norway)

\section{Section 3: Workforce model}

Twenty-three nurses reported that 1-5 staff members were allocated for bereavement follow-up. Most ICUs allocated 1-2 hours a week for bereavement follow-up. A range of staff members were 
allocated to, or took responsibility for, follow-up. Most frequently these were bedside ICU nurses, followed by clinical nurse specialists, ward clerks, nurse managers, head physicians, nurse researchers, and nurse educators. Most of the allocated staff provided follow-up on a permanent basis, rather than rotating the job among colleagues. Most commonly, bereavement follow-up was the responsibility of the nurse caring for the patient at the time of death. Some units offered debriefing for the nurses after a traumatic death. Narrative responses describing the responsibility for follow-up:

"The individual ICU-nurse. One nurse is responsible for informing new nurses and annual status" (ID06 Norway)

"Any nurse or intensive care nurse who had the patient when he/she died" (ID25 Norway)

"The nurse caring for the patient when he died contacts the family for follow-up" (ID59 Norway)

"The social worker" (ID07 Sweden)

"ICU nurse and doctors. All staff are responsible, it depends on who was involved in the patient" (ID49 Denmark)

"So far we don't have a bereavement follow up service, nor a team or person responsible." (ID71 Netherlands)

"We are working on a protocol to introduce in this domain of aftercare" (ID20 Netherlands)

\section{Section 4: Evaluation model}

Only 9 respondents reported that follow-up services were evaluated at their unit. Reported methods of evaluation included interviews or surveys with staff or relatives. Five respondents reported changes made to the bereavement services after evaluation. According to the respondents, the services most appreciated by the relatives were: memorial services (to remember the patient), a 
follow-up visit to ICU (to thank the staff), a chance to talk to the nurse and physician caring for the patient (to obtain closure), a phone call from the nurse (to ask questions), reading the ICU diary with the nurse (to understand what happened), printed information about support after the patient's death. No elements were considered unnecessary by the relatives. The respondents described the elements that were most appreciated by the families:

"Memorial service" (ID03 England)

"To thank the staff" (ID43 Norway)

"The talk with the nurses and doctors afterwards" (ID45 Netherlands)

"Talking about the patient with the nurses" (ID46 Netherlands)

"The call and the visit" (ID56 Sweden)

"The phone call after death" (ID59 Norway)

"Diary and visit" (ID60 Norway)

"A booklet made to help us to find [practical] information" (ID79 France)

Some nurses stated that guidelines were needed for bereavement follow-up in ICU. Some additional narrative responses were:

"I am disappointed that I work in a critical care unit, which does not provide bereavement service/follow-up" (ID09 N Ireland)

"I wish it was in place in our ICU and would be recognized as important element in patient follow-up" (ID11 Ireland)

"We do not have an institutional bereavement follow up service, maybe this is due to very low mortality rates on our unit"' (ID15 Germany)

"We hope to start such a service in our unit, but we would like to know more on how to do it best" (ID19 Denmark) 


\section{DISCUSSION}

The aim of the study was to explore elements, organization, and evaluation of ICU bereavement services in European countries. The main finding was that a variety of elements of bereavement support were offered in European ICUs, mostly Northern Europe, and that formalized bereavement support is often lacking. Our study showed that viewing the deceased in ICU, rather than the hospital mortuary, was common practice. This finding is consistent with other studies (Coombs et al. 2017, Egerod et al. 2018, Mitchell et al. 2017, Valks et al. 2005), albeit some nurses felt pressured to move the body to make room for the next patient (Bloomer et al., 2013).

Other common elements of bereavement support identified in the present study included a supportive phone call to the family or arranging a follow-up visit to ICU. This was consistent with earlier studies (Coombs et al. 2017, Egerod et al. 2018) showing that calling the family or sending a card of sympathy some weeks after the death of the patient is common practice. The importance of a follow-up meeting with the ICU team has been demonstrated, particularly if the physician is present (Kock et al. 2014). Condolence letters have also been described as meaningful to the family. Condolence letters were investigated in 22 ICUs in France using qualitative and quantitative methodology. A thematic analysis showed that letters of condolence could provide a feeling of support, humanization of the medical system, an opportunity for reflection, an opportunity to describe their loved one, continuity and closure, or created doubts and ambivalence (Kentish-Barnes et al. 2017b). The associated multicenter trial, however, could not demonstrate a positive effect of condolence letters, and even suggested worsening of depression and symptoms of posttraumatic stress (Kentish-Barnes et al. 2017a). This demonstrates the importance of investigating benefits and harms of nursing interventions. 
Families have many questions and concerns after the loss of a close family member in hospital and need answers to obtain closure. One study showed that families had questions about the diagnosis, the final moments before death, outcomes of alternative treatments, of life decisions, and communication of death (Lebus et al. 2014). It was concluded that a specialized bereavement service should allow follow-up of relatives with ongoing questions and concerns to alleviate reactions of severe grief. Some respondents in our survey provided the bereaved family with the diary written by the nurses to the patient in ICU. Similarly, a recent study suggested giving the family of non-survivors the ICU diary as a 'survival kit' to gain coherence and understanding and as bereavement support (Johansson et al. 2018). The study provided some qualitative evidence of the usefulness of the diary.

According to the nurses surveyed there is need for a guideline for bereavement services in ICU. Although guidelines are common for bereavement support in palliative and cancer care, they are still uncommon in non-malignant diseases (Egerod et al., 2019) and the intensive care setting. A scoping review of bereavement service outcomes showed that most services were related to educational information and emotional support and stressed the importance of effective bereavement services (Wilson et al., 2017). In the general wards, the focus of bereavement support is on reducing the level of grief, distress, depression or somatization of physical symptoms in the bereaved, or increasing their grief knowledge. The scoping review, however, suggested that most programs were unsuccessful in alleviating grief (Wilson et al., 2017). More research is needed to understand what the family needs from the ICU staff and to test the efficacy of interventions in bereavement follow-up. A recent review concluded that evidence is lacking to provide recommendations for the most acceptable and effective bereavement support and that clinicians need to be adequately trained for delivery of support (Efstathiou et al. 2019). We recommend 
participant involvement to identify the most relevant elements of bereavement follow-up and systematic evaluation of the services.

Management of grief should perhaps be an integral part of family-centered care in ICU (Davidson et al. 2017). Post Intensive Care Syndrome - Family (PICS-F) shows that family members of ICU patients acquire psychological and physical illness from worry and grief (Davidson et al. 2012). Studies show that complicated grief is debilitating and should be prevented (Gries et al. 2010). Death in ICU can be expected or unexpected, where expected death can be the result of End-of-Life decisions. One study shows that End-of-Life discussions are associated with less aggressive medical treatment near death, and that aggressive care is associated with worse bereavement adjustment (Wright et al. 2008). In our study we have not looked at bereavement in context, i.e. whether death was expected. End-of-Life guidelines are in place in many units and we might suggest that Bereavement support guidelines should be an integral part of ICU services.

\section{Limitations}

The response rate on our study was low, and this may have been influenced by several factors. We were unable to add the questionnaire to the conference package and chose to hand it out during the opening ceremony of the Congress and not all delegates were present during this ceremony.

Distributing questionnaires during a congress is a relatively easy and accessible recruitment strategy, but our results might have been biased by uneven distribution of delegates as most were from Northern European countries, and some ICUs were represented by more than one delegate. Although our sample was unevenly distributed, we were able to describe important elements of bereavement follow-up across intensive care units in Europe. Our survey was anonymous, and we were unable to determine if respondents worked at the same ICU. This would be a drawback if we 
aimed to quantify services in each country. For this reason, it was less important to describe how many ICUs provided each element than to describe the general content and intent.

\section{CONCLUSION}

Bereavement services are still not standardized at European ICUs, but the elements of services are similar across countries. We recommend the development and implementation of bereavement follow-up guidelines for intensive care units. User involvement and service evaluation are necessary to ensure relevant elements of services.

\section{Conflicts of interest}

The authors have no conflicts of interest to declare.

\section{WHAT IS KNOWN ABOUT THIS TOPIC}

- Many families experience the death of a loved one in ICU

- Bereavement services are offered at some ICUs

\section{WHAT THIS PAPER ADDS}

- Bereavement services are not systematically offered in European ICUs

- Culture-specific guidelines are needed for bereavement follow-up in ICU

- Common elements of bereavement services have been identified, e.g. viewing the deceased in the unit, providing follow-up information, sending a letter of sympathy, and calling the family to arrange a meeting

- Consequences of bereavement in ICU have been discussed, e.g. prolonged or complicated grief and lack of closure in the bereaved 


\section{REFERENCES}

Anderson WG, Arnold RM, Angus DC, Bryce CL. (2008). Posttraumatic stress and complicated grief in family members of patients in the intensive care unit. Journal of General Internal Medicine; 23: 1871-1876.

Azoulay E, Pochard F, Kentish-Barnes N, Chevret S, Aboab J, Adrie C, Annane D, Bleichner G, Bollaert PE, Darmon M, Fassier T, Galliot R, Garrouste-Orgeas M, Goulenok C, GoldgranToledano D, Hayon J, Jourdain M, Kaidomar M, Laplace C, Larche J, Liotier J, Papazian L, Poisson C, Reignier J, Saidi F, Schlemmer B. (2005). Risk of post-traumatic stress symptoms in family members of intensive care unit patients. American Journal of Respiritory Critical Care Medicine; 171: 987-994.

Bloomer MJ, Morphet J, O'Connor M, Lee S, Griffiths D. (2013). Nursing care of the family before and after a death in the ICU - an exploratory pilot study. Australian Critical Care; 26: 2328.

Coombs M, Mitchell M, James S \& Wetzig K (2017): Intensive care bereavement practices across New Zealand and Australian intensive care units: a qualitative content analysis. J Clin Nurs 26, 2944-2952.

Coombs MA, Addington-Hall J, Long-Sutehall T. (2012). Challenges in transition from intervention to end of life care in intensive care: a qualitative study. International Journal of Nursing Studies; 49: 519-527.

Cuthbertson BH, Rattray J, Johnston M, Wildsmith JA, Wilson E, Hernendez R, Ramsey C, Hull AM, Norrie J, Campbell M. (2007). A pragmatic randomised, controlled trial of intensive care follow up programmes in improving longer-term outcomes from critical illness. The PRACTICAL study. BMC Health Services Research; 7: 116.

Davidson JE, Aslakson RA, Long AC, Puntillo KA, Kross EK, Hart J, Cox CE, Wunsch H, Wickline MA, Nunnally ME, Netzer G, Kentish-Barnes N, Sprung CL, Hartog CS, Coombs M, Gerritsen RT, Hopkins RO, Franck LS, Skrobik Y, Kon AA, Scruth EA, Harvey MA, Lewis-Newby M, White DB, Swoboda SM, Cooke CR, Levy MM, Azoulay E \& Curtis JR (2017): Guidelines for Family-Centered Care in the Neonatal, Pediatric, and Adult ICU. Crit Care Med 45, 103-128.

Davidson JE, Jones C \& Bienvenu OJ (2012): Family response to critical illness: postintensive care syndrome-family. Crit Care Med 40, 618-624.

Efstathiou N, Walker W, Metcalfe A \& Vanderspank-Wright B (2019): The state of bereavement support in adult intensive care: A systematic review and narrative synthesis. J Crit Care; 50: 177-187.

Egerod I, Kaldan G, Shaker SB, Guldin MB, Browatski A, Marsaa K \& Overgaard D (2019): Spousal bereavement after fibrotic interstitial lung disease: A qualitative study. Respir Med 146, $129-136$

Egerod I, Kaldan G, Coombs M, Mitchell M. (2018). Family-centered bereavement practices in Danish intensive care units: a cross-sectional national survey. Intensive and Critical Care Nursing; 45: 52-57.

Garland S. (2011). A service to support bereaved families. Nursing New Zealand; 17: 17. 
Goldfarb MJ, Bibas L, Bartlett V, Jones H \& Khan N. (2017). Outcomes of Patient- and FamilyCentered Care Interventions in the ICU: A Systematic Review and Meta-Analysis. Crit Care Med 45, 1751-1761.

Gries CJ, Engelberg RA, Kross EK, Zatzick D, Nielsen EL, Downey L \& Curtis JR (2010): Predictors of symptoms of posttraumatic stress and depression in family members after patient death in the ICU. Chest 137, 280-287.

Johansson M, Wahlin I, Magnusson L, Runeson I \& Hanson E (2018): Family members' experiences with intensive care unit diaries when the patient does not survive. Scandinavian Journal of Caring Science; 32: 233-240.

Kentish-Barnes N, Chevret S, Champigneulle B, Thirion M, Souppart V, Gilbert M, Lesieur O, Renault A, Garrouste-Orgeas M, Argaud L, Venot M, Demoule A, Guisset O, Vinatier I, Troche G, Massot J, Jaber S, Bornstain C, Gaday V, Robert R, Rigaud JP, Cinotti R, Adda M, Thomas F, Calvet L, Galon M, Cohen-Solal Z, Cariou A \& Azoulay E (2017a): Effect of a condolence letter on grief symptoms among relatives of patients who died in the ICU: a randomized clinical trial. Intensive Care Medicine; 43: 473-484.

Kentish-Barnes N, Cohen-Solal Z, Souppart V, Galon M, Champigneulle B, Thirion M, Gilbert M, Lesieur O, Renault A, Garrouste-Orgeas M, Argaud L, Venot M, Demoule A, Guisset O, Vinatier I, Troche G, Massot J, Jaber S, Bornstain C, Gaday V, Robert R, Rigaud JP, Cinotti R, Adda M, Thomas F \& Azoulay E (2017b): "It Was the Only Thing I Could Hold Onto, But...": Receiving a Letter of Condolence After Loss of a Loved One in the ICU: A Qualitative Study of Bereaved Relatives' Experience. Crit Care Medicine; 45: 1965-1971.

Kock M, Berntsson C \& Bengtsson A (2014): A follow-up meeting post death is appreciated by family members of deceased patients. Acta Anaesthesiologica Scandinavica; 58: 891-896.

Lautrette A, Darmon M, Megarbane B, Joly LM, Chevret S, Adrie C, Barnoud D, Bleichner G, Bruel C, Choukroun G, Curtis JR, Fieux F, Galliot R, Garrouste-Orgeas M, Georges H, Goldgran-Toledano D, Jourdain M, Loubert G, Reignier J, Saidi F, Souweine B, Vincent F, Barnes NK, Pochard F, Schlemmer B, Azoulay E. (2007). A communication strategy and brochure for relatives of patients dying in the ICU. New England Journal of Medicine; 356: $469-478$.

Lebus C, Parker RA, Morrison K, Fraser D \& Fuld J (2014): Families' concerns after bereavement in hospital: what can we learn? J Palliat Med 17, 712-717.

McAdam JL, Erikson A. (2016). Bereavement Services Offered in Adult Intensive Care Units in the United States. American Journal of Critical Care; 25: 110-117.

Mitchell M, Coombs M \& Wetzig K (2017): The provision of family-centred intensive care bereavement support in Australia and New Zealand: Results of a cross sectional explorative descriptive survey. Aust Crit Care 30, 139-144.

Mitchell M, Coombs M, Wetzig K. (2016). The provision of family-centred intensive care bereavement support in Australia and New Zealand: Results of a cross sectional explorative descriptive survey. Australian Critical Care; 30: 139-144.

Needham DM, Davidson J, Cohen H, Hopkins RO, Weinert C, Wunsch H, Zawistowski C, BemisDougherty A, Berney SC, Bienvenu OJ, Brady SL, Brodsky MB, Denehy L, Elliott D, Flatley C, Harabin AL, Jones C, Louis D, Meltzer W, Muldoon SR, Palmer JB, Perme C, Robinson M, Schmidt DM, Scruth E, Spill GR, Storey CP, Render M, Votto J, Harvey MA. 
(2012). Improving long-term outcomes after discharge from intensive care unit: report from a stakeholders' conference. Critical Care Medicine; 40: 502-509.

Nielsen MK, Neergaard MA, Jensen AB, Bro F, Guldin MB. (2016). Psychological distress, health, and socio-economic factors in caregivers of terminally ill patients: a nationwide populationbased cohort study. Supportive Care in Cancer; 24: 3057-3067.

Pochard F, Darmon M, Fassier T, Bollaert PE, Cheval C, Coloigner M, Merouani A, Moulront S, Pigne E, Pingat J, Zahar JR, Schlemmer B, Azoulay E. (2005). Symptoms of anxiety and depression in family members of intensive care unit patients before discharge or death. A prospective multicenter study. Journal of Critical Care; 20: 90-96.

Ross MW. (2008). Implementing a bereavement program. Critical Care Nurse; 28: 88, 87.

Siegel MD, Hayes E, Vanderwerker LC, Loseth DB, Prigerson HG. (2008). Psychiatric illness in the next of kin of patients who die in the intensive care unit. Critical Care Medicine; 36: $1722-1728$.

Stroebe M, Schut H, Stroebe W. (2007). Health outcomes of bereavement. Lancet; 370: 1960-1973.

Vaismoradi M, Turunen H, Bondas T. (2013). Content analysis and thematic analysis: Implications for conducting a qualitative descriptive study. Nursing in Health Science; 15: 398-405.

Valks K, Mitchell ML, Inglis-Simons C, Limpus A. (2005). Dealing with death: an audit of family bereavement programs in Australian intensive care units. Australian Critical Care; 18: 148151.

Williams R, Harris S, Randall L, Nichols R, Brown S. (2003). A bereavement after-care service for intensive care relatives and staff: the story so far. Nursing in Critical Care; 8: 109-115.

Wilson DM, Dhanji N, Playfair R, Nayak SS, Puplampu GL, Macleod R. (2017). A scoping review of bereavement service outcomes. Palliative and Supportive Care; 15: 242-259.

WMA. (2008). World medical association declaration of Helsinki. Ethical principles for medical research involving human subjects. https://www.wma.net/wpcontent/uploads/2018/07/DoH-Oct2008.pdf (accessed 08/03/2019).

Wright AA, Zhang B, Ray A, Mack JW, Trice E, Balboni T, Mitchell SL, Jackson VA, Block SD, Maciejewski PK \& Prigerson HG (2008): Associations between end-of-life discussions, patient mental health, medical care near death, and caregiver bereavement adjustment. Jama 300, 1665-1673. 